\title{
Testing social learning in a wild mountain parrot, the kea (Nestor notabilis)
}

\author{
GYULA K. GAJDON, NATASHA FIJN, and LUDWIG HUBER \\ University of Vienna, Vienna, Austria
}

\begin{abstract}
Huber, Taborsky, and Rechberger (2001) reported an experiment in which the efficiency with which captive keas opened a complex food container was increased by observation of a skilled conspecific. However, only testing social learning in free-ranging animals can demonstrate social learning in natural conditions. For that purpose, a tube-lifting paradigm was developed and tested on keas both in captivity and in Mount Cook National Park, New Zealand. The task was to remove a tube from an upright pole in order to gain access to a reward inside the tube. The top of the pole was higher than a standing kea, so that, to remove the tube, an individual had to simultaneously climb onto the pole and manipulate the tube up the pole with its bill. Because only 1 naive bird managed to remove a tube twice in 25 halfhour sessions and disappeared after success, another bird was trained to solve the task and to provide demonstrations for others. Even under such conditions, only 2 of at least 15 birds learned to remove the tube in 28 sessions. There was no indication that observer birds' use of bill and feet when exploring the tube changed as the number of observations of tube removal increased in a way that would, in principle, increase the likelihood of tube removal. The results suggest a dissociation of social learning potential as assessed in laboratory animals, and social transmission of foraging techniques in natural populations.
\end{abstract}

Examples of social influence on the behavior of animals are widespread, diverse, and exciting. Observation of conspecifics can lead to synchrony in the performance of established behavior or, through diverse forms of social learning, to the transmission of innovations throughout a group (Galef, 1988; Lefebvre, 2000; Whiten \& Ham, 1992; Zentall, 1996). Early works (Fischer \& Hinde, 1949; Hinde \& Fischer, 1951) provided indications of social learning of visually perceived tasks in free-ranging birds, yet these studies were not experimental and, when analyzed in detail, seemed not to involve cognitively more demanding forms of social learning (Sherry \& Galef, 1990).

More recently, rigorous experimental procedures have provided strong evidence that birds are able to engage in different forms of social learning, such as stimulus enhancement (Fritz, Bisenberger, \& Kotrschal, 2000; Fritz \& Kotrschal, 1999b), imitation (Akins \& Zentall, 1996, 1998; Fawcett, Skinner, \& Koldsmith, 2002; Kaiser, Zen-

This study was financed by the Austrian Science Fund (BIO P15027). Banding permission was received from the Department of Conservation of New Zealand (CHH 12/129 and CA/282/FAU). We are grateful for the assistance and support of the Department of Conservation of New Zealand, especially that of Ray Bellringer, Phil Crutchley, and Kerry Weston from the Mount Cook Area Office and Andy Grant from the Christchurch Conservancy Office. Thanks to Robert Jackson for contacts within New Zealand, to Bernhard Voelkl and M. Tuulia Ortner for their help in the field, and to M. Tuulia Ortner for her additional contribution to the design of the test apparatus. Thanks also to Jeff Galef and an unknown referee for comments on the manuscript. Correspondence concerning this article should be addressed to G. K. Gajdon, Department of Developmental and Theoretical Biology, University of Vienna, Althanstrasse 14, A-1090, Vienna, Austria (e-mail: gyula_gajdon@ hotmail.com). tall, \& Galef, 1997; Zentall, 1996), and emulation (Huber, Taborsky, \& Rechberger, 2001). Early experimental indication came from Dawson and Foss's (1965) demonstration that budgerigars use either the foot or the bill in a lidremoval task according to their demonstrator's method. Since then, this two-action method has been further elaborated and has become one of the standard methods in experimental investigations of imitation (Bugnyar \& Huber, 1997; Fawcett et al., 2002; Heyes \& Dawson, 1990; Voelk1 $\&$ Huber, 2000; Whiten \& Custance, 1996).

It has been claimed that additional emphasis should be given to social learning in groups rather than in separate individuals, as is required by many laboratory paradigms (Coussi-Korbel \& Fragaszy, 1995). This claim was made in awareness that testing in groups, although weakening our ability to distinguish between particular forms of social learning, would clarify the relevance of social learning to more natural situations (Nicol \& Pope, 1994). In laboratory studies conducted on birds, aspects of social learning in groups have been investigated (e.g., Fritz \& Kotrschal, 1999a, 1999b; Giraldeau \& Lefebvre, 1987; Lefebvre \& Giraldeau, 1994; Nicol \& Pope, 1994). Nevertheless, experimental evidence from free-ranging animals is needed, because a combination of laboratory and field experiments provides an opportunity for a more integrative approach to understanding social learning (Carlier \& Lefebvre, 1997; Dolman, Templeton, \& Lefebvre, 1996; Rosenblum, Kummer, Nadler, Robinson, \& Suomi, 1989).

The kea (Nestor notabilis) provides a good model for experimental investigations in the field, since it is a highly explorative bird with an almost total lack of neophobia 
(Keller, 1975; Kubat, 1992; Temple, 1996). This olivegreen parrot with bold orange-red underwing coverts is endemic to South Island, New Zealand. It lives in the mountainous areas of southern beech (Nothofagus) forest, subalpine scrub, and alpine grassland (Jackson, 1960, 1963; Wilson, 1990). The kea forages on more than 100 species of plant (see, e.g., Brejaart, 1988; Clark, 1970), catches insects, and scavenges on carcasses and human rubbish. Exploration behavior, especially of young animals, has destructive effects on human settlements, such as mountain huts and ski fields.

In comparison with its closest relative, the kaka (Nestor meridionalis), which inhabits temperate forests at lower altitudes, the kea has an extended juvenile period (Diamond \& Bond, 1999). After up to 5 months of dependence on their parents, young kea live in social flocks until they form breeding pairs at the age of 4-5 years (Jackson, 1960, 1963; Temple, 1996). Diamond and Bond (1999) hypothesized that this prolonged immature period, during which kea may continue to solicit food from older birds by hunching displays, is needed to learn the skills required to survive in their harsh environment.

Thus, the kea fulfills many conditions believed to favor social learning: extended parental association, extreme iteroparity, group foraging, opportunism, curiosity, and potentially long life span (Lefebvre, 2000; Richardson \& Boyd, 2000). Indeed, convincing evidence of a potential for social learning in keas was recently provided by an experiment with captive birds (Huber et al., 2001). Young keas managed to open significantly more locks on a food box when given the opportunity to observe a skilled demonstrator than when not given such an opportunity. Observers were quicker to approach the locking devices and exhibited extended persistence in their manipulative actions (see also Fritz et al., 2000, for a study of graylag geese, Anser anser). However, not all locking devices were explored for longer periods by observers than by non-observers. Bolts were explored for equally long periods by both groups. Nevertheless, only observers were able to remove bolts from latches, although there was no indication of imitation by observers, since the sequence and topography of the observers' behavior did not match the behavior of their models. Huber et al. (2001) concluded that the keas learned by emulation - that is, that they learned about the change in the environment caused by a demonstrator's behavior (Call \& Carpenter, 2002; Tomasello, 1990).

The present study was undertaken using an operant task to examine social learning in a free-ranging kea. In contrast to Huber et al. (2001), our aim was not to distinguish among the many forms of social learning but, more generally, to investigate whether and how a problem that is unlikely to be solved by naive birds would be solved by other birds after observation of a skilled demonstrator. On the basis of observations made during their field studies, Diamond and Bond (1999) suggested that, because keas' natural foraging actions are very simple, they master tasks primarily through trial and error, and observational learn- ing plays a minimal role. However, innovation in foraging techniques may not be a frequent event in wild keas. Therefore, we investigated it experimentally.

A tube-removal paradigm was developed, and the apparatus was presented to keas in Mount Cook National Park, New Zealand. Since there were always several birds in the area where the apparatus was presented, both stimulus enhancement and individual trial and error could take place. After estimation of the rate of tube removal from baseline data, 1 bird was trained in the wild to solve the task, and thereafter provided demonstrations (test phase). Exploration behavior and success rate during baseline and test phase, as well as changes in exploration behavior in the course of the test phase, were compared.

The task was to remove a tube from an upright pole fixed on a wooden platform. Butter, a highly preferred food for kea, was smeared on the inner side of the tube. Only when the tube was removed from the pole could the birds gain full access to the reward. The pole was high enough so that the task could not be completed by an individual pushing the tube up the pole with its bill. Instead, an individual had to climb onto the pole and simultaneously manipulate the tube up the pole with its bill.

This task provided several advantages. First, a bird climbing and manipulating an object up a pole with its bill is conspicuous and easily seen in the field, even from a great distance. Second, the task takes the bird a few seconds to complete, and although this is not very long in comparison with, for example, pulling out an iron pin from a lock, tube removal is not completed in an instant. On the other hand, the task does not take so long that observers lose interest.

An important consideration was that the task was not solved entirely with the bill. Instead, the task required movement of both the bill and the feet. This may be important, because the behavioral repertoire of the kea includes many actions with the bill, and all of themtearing, pushing, biting, scraping, and so on (Keller, 1974; Potts, 1969) — are likely to have been performed previously during feeding. However, the need to combine feet and bill actions, as well as the task of moving an object along a pole, are unlikely to be part of the foraging repertoire of wild kea.

\section{METHOD}

\section{Study Animals}

Free-ranging keas regularly frequent a large, multistoried hotel in Mount Cook Village on South Island, New Zealand (elevation, 725 m; annual rainfall, approximately 5,000 $\mathrm{mm}$ ). Keas in Mount Cook National Park gather at a number of locations in the vicinity of the hotel, mainly early in the morning.

Experiments were conducted wherever keas tended to congregate. Two key locations were a hotel car park, where keas forage on food scraps from rubbish bins (18 sessions), and an elevated feature between the hotel and nearby native vegetation (23 sessions). Other, less frequently used (12 sessions) locations were in Mount Cook Village, near Sealy Tarns at the upper boundary of alpine scrubland (elevation, $500 \mathrm{~m}$ above the village) and outside Mueller hut (elevation, $1,000 \mathrm{~m}$ above the village). 
In March 2002, we began banding the birds with two colored aluminum bands on one leg and a stainless steel band from the National Museum of New Zealand on the other. Age class and sex were determined according to phenotype (Bond, Wilson, \& Diamond, 1991; Mallet, cited in Higgins, 1999). Baseline data were collected from July to October 2002 during 2-week blocks in each month. Test phase sessions were conducted from January 2003 to February 2003.

\section{Experimental Apparatus}

The apparatus consisted of a pole (length, $70 \mathrm{~cm}$; diameter, $20 \mathrm{~mm})$ attached to a platform $(60 \mathrm{~cm} \times 45 \mathrm{~cm})$. An individual kea standing on the platform could not reach the top of the pole with its bill. The $60^{\circ}$ angle between the platform and the pole enabled the kea to climb the pole (Figure 1).

The tube consisted of inner and outer tubes (both approximately $7 \mathrm{~cm}$ in length). The inner tube ( $32 \mathrm{~mm}$ in diameter) was made of gray, flexible plastic tubing with riffles, and it could slide up and down the pole easily. The outer tube was constructed of stiffer, 2 -mm-thick gray plastic tubing ( $40 \mathrm{~mm}$ in diameter) that was tough enough to avoid damage as a result of manipulation by kea. A rivet inserted through holes drilled halfway down one side of each tube held the tubes together when a kea slid the tubes up and down the pole. Butter was smeared on the inner tube. Then, the outer tube was placed over the inner tube and the rivet was inserted through the holes in both tubes.

The birds could taste traces of butter by probing the clean edges of the tubes, and they were likely to smell it (Kubat, 1992). Thus, all birds exploring the tubes knew that there was food inside the tube. However, they had access to the reward only when the tube was removed from the pole, the rivet had fallen out, and the inner and outer tubes were separated.

\section{Procedure}

The birds were provided with the apparatus in any weather other than extreme conditions (such as snow or thunderstorms). The apparatus was offered whenever birds were present around Mount
Cook Village, usually for the first $2 \mathrm{~h}$ after dawn (42 of 53 sessions) and $1 \mathrm{~h}$ before sunset ( 8 sessions). Experiments were conducted only if there was adequate light to positively identify individual color bands on the birds.

At the start of each test, the experimenter did a scan sample of birds present, then placed both tubes (held together by the rivet) over the top of the pole and concealed the tubes with the hand while sliding the tubes down to the bottom of the pole. When a bird started to climb the pole and before it removed the tube, the experimenter scanned for individuals that showed signs of observing tube removal by interrupting ongoing activity and directing attention toward the bird removing the tube. After a bird had removed the tube, it was given 2 min to explore and scrape off butter. After 2 min, the tubes and rivet were retrieved by the experimenter, and new tubes were placed on the pole. During baseline sessions, any birds that were present had access to the apparatus, limited only by individual status within group hierarchy.

During the test phase, after the demonstrator had removed tubes from the pole a number of times, the demonstrator or other birds that had solved the task (which then became demonstrators) were prevented from approaching the apparatus, to give other birds the opportunity to explore the apparatus. To prevent a bird from approaching the apparatus, the experimenter stood between the bird and the apparatus and kept this position by moving around the apparatus according to the position of the bird. Only a few gentle movements toward a bird by the experimenter were needed to prevent it from approaching, and the other birds remained calm.

All tests were recorded using a digital video camera on a tripod. Recording was paused if all birds moved away from the platform or ended when they did not return (i.e., when they flew away) or when 30 min of continuous exploration at the apparatus had elapsed without tube removal.

\section{Training of Initial Demonstrator}

Juvenile male White was chosen as a suitable demonstrator. This juvenile male was not top ranking and was unlikely to monopolize

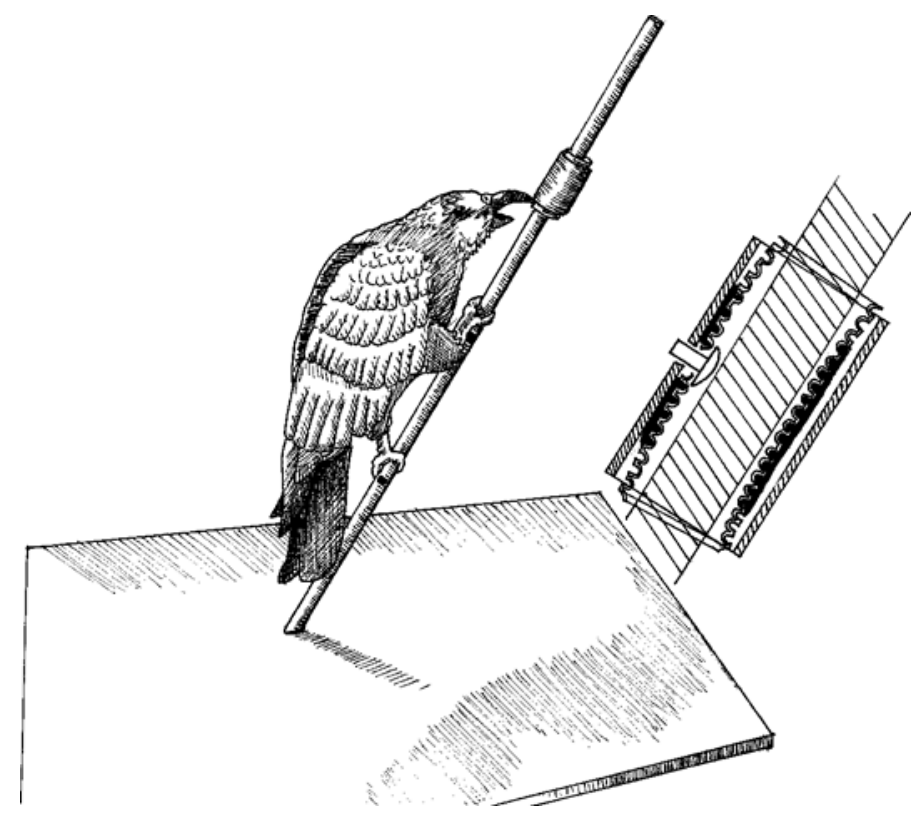

Figure 1. Apparatus with a kea climbing the pole while manipulating the tube up the pole with its bill (drawn from a photo). Detail: Sectional view of pole and outer tube (hatched), inner tube with butter (black), and rivet connecting outer and inner tubes. 
the experimental apparatus. This particular bird, although not seen every day, frequented the village regularly.

As a first step, the chosen bird was given butter rewards. After a few such feedings, we were able to attract him away from other birds present, and he readily followed an experimenter behind a building of the hotel, where training of tube removal took place. Training was interrupted when other birds were seen or were likely to approach.

Training started with a tube on a pole that was so short $(15 \mathrm{~cm})$ that the tube was easily removed from the pole by the bird. Increasingly longer poles $(30,50$, and $70 \mathrm{~cm})$ were then used. We kept male White attentive and in a playful, exploratory mood by tossing up small objects that were lying around-a behavior that keas perform during playand the bird joined in tossing the objects. With this procedure, we were able to train the juvenile male to solve the task in seven sessions within 1 week at the end of December 2002. No other bird observed the training. The trained bird (henceforth labeled "Model White ) readily performed demonstrations in the presence of other birds.

\section{Analyses}

For each individual bird, video recordings were scanned for the following behaviors: presence at test location; length of time an individual stayed within one body length of the apparatus; proportion of time spent exploring the tube (bill contact with the tube not interrupted for longer than $1 \mathrm{sec}$ ); proportion of time spent with a foot on the pole while exploring the tube; proportion of time spent climbing the pole while exploring the tube (alternating movements of both feet on the pole); proportion of time spent sliding the tube in relation to time spent exploring the tube; proportion of time the tube stayed at the base, second, third, and top quarters of the pole while being explored; events of tube removal; and signs that birds nearby observed tube removal. Nonparametric two-tailed tests and a .05 level of significance were used. The results are given as medians and quartiles $Q 1$ and $Q 3$.

\section{RESULTS}

\section{Baseline and Test Phase Sessions}

The birds were given 16 baseline sessions which together comprised 367 investigation events (defined as the presence of a bird within one body length of the apparatus) by 14 known individuals plus other, unbanded keas. The median total numbers (and quartiles) of banded and unbanded birds present per session were 4.5 (3-7.25) and $1(0-2.25)$, respectively.

After baseline, there were nine additional sessions in which a screw was inserted into the pole below the elevated tube, $21 \mathrm{~cm}$ (three sessions) or $35 \mathrm{~cm}$ (six sessions) above the base of the pole, to encourage the birds to climb the pole and solve the task. There were 137 investigation events during these sessions, which involved 7 banded birds. The median total numbers (and quartiles) of banded and unbanded birds present per session were 5 (4.5-7) and 0 $(0-0)$, respectively.

In the test phase, after the model was trained, there were 335 investigation events in 28 sessions (with 12 banded birds). The median total numbers (and quartiles) of banded and unbanded birds present per session were 6 (4-9.25) and $1(0-2)$, respectively. Excluding events of the model bird and other birds after they had solved the task for the first time, there were 223 investigation events during the test phase and 329 events in the baseline sessions.

Table 1 shows the time individuals spent within one body length of the apparatus during the different phases of the experiment. Unbanded birds were pooled as 1 individual labeled "unknown. There was no significant difference of investigation duration between baseline and test phase individuals (Mann-Whitney $U$ test: $U=73, N_{1}=$ $\left.15, N_{2}=12, p=.41\right)$.

\section{Baseline}

In addition to the birds that stayed within sight of the apparatus, as many as 4 birds were seen simultaneously within one body length of the apparatus. The median proportion of time during which more than 1 bird stayed close to the apparatus was .26 (.14-.49) per baseline session.

Table 1

Time Individuals Spent Exploring the Apparatus During Different Experimental Phases and Proportion of Time Spent in Different Activities

\begin{tabular}{|c|c|c|c|c|}
\hline Experimental Phase & $N$ & Median & $Q 1$ & $Q 3$ \\
\hline & & \multicolumn{3}{|c|}{ Investigation Duration (Sec) } \\
\hline Baseline & 15 & 1,396 & 111 & 2,237 \\
\hline Screw sessions & 8 & 1,714 & 278 & 2,400 \\
\hline Test phase & 12 & 839.5 & 87.75 & $1,681.75$ \\
\hline \multirow[t]{2}{*}{ Solvers } & 3 & 606 & 125 & 825 \\
\hline & & \multicolumn{3}{|c|}{$\begin{array}{l}\text { Proportion of Time } \\
\text { Exploring Tube }\end{array}$} \\
\hline Baseline & 15 & .47 & .17 & .62 \\
\hline Screw sessions & 8 & .40 & .22 & .56 \\
\hline Test phase & 12 & .45 & .16 & .60 \\
\hline \multirow[t]{2}{*}{ Solvers } & 3 & .54 & .43 & .81 \\
\hline & & \multicolumn{3}{|c|}{$\begin{array}{l}\text { Proportion of Time } \\
\text { Moving Tube }\end{array}$} \\
\hline Baseline & 15 & .09 & .05 & .12 \\
\hline Screw sessions & 8 & .04 & .04 & .08 \\
\hline Test phase & 11 & .14 & .04 & .23 \\
\hline \multirow[t]{2}{*}{ Solvers } & 3 & .64 & .56 & .78 \\
\hline & & \multicolumn{3}{|c|}{ PTFP } \\
\hline Baseline & 15 & $.02^{a, b}$ & .00 & .07 \\
\hline Screw sessions & 8 & $.25^{\mathrm{a}}$ & .07 & .35 \\
\hline Test phase & 11 & $.10^{\mathrm{b}}$ & .07 & .27 \\
\hline \multirow[t]{2}{*}{ Solvers } & 3 & .08 & .06 & .17 \\
\hline & & \multicolumn{3}{|c|}{$\begin{array}{c}\text { PTFP While Tube Was Above } \\
\text { Base Quarter of Pole }\end{array}$} \\
\hline Baseline & 11 & .03 & .00 & .06 \\
\hline Test phase & 9 & .03 & .00 & .17 \\
\hline \multirow[t]{2}{*}{ Solvers } & 3 & .06 & .06 & .27 \\
\hline & & \multicolumn{3}{|c|}{$\begin{array}{l}\text { Proportion of Time } \\
\text { Climbing With Tube }\end{array}$} \\
\hline Baseline & 15 & $.00^{c}$ & .00 & .00 \\
\hline Screw sessions & 8 & $.01^{\mathrm{c}}$ & .00 & .02 \\
\hline Test phase & 11 & .00 & .00 & .00 \\
\hline Solvers & 3 & .30 & .11 & .42 \\
\hline
\end{tabular}

Note $-N$ is number of individuals. "Investigation is defined as the individual's being within one body length of the apparatus. "Proportion of time moving tube and "PTFP (proportion of time feet on pole) refer to time spent exploring the tube. Significantly different data $(p<.05)$ are labeled with a pair of the same letter (Mann-Whitney $U$ test). For the test phase, the data of Solver Orange and Solver Green were not considered after they had removed the tube for the first time. Their data after first tube removal and those of trained Model White are shown in the "Solvers rows. Postsuccess data of the only bird that was successful and those of the only other observer during baseline sessions are excluded from the "Baseline row. 
Thus, there were many opportunities for keas to watch other birds manipulating the tube. When there were several birds within one body length of the apparatus, 2 birds seldom manipulated the tube at the same time (proportion of duration per session: median, .02; quartiles, $0-.06 ; n=$ 16) and joint action was quickly terminated by the dominant bird's displacing its subordinate.

Only 1 individual solved the task during the baseline sessions, in Session 6. This fledgling male removed a second tube in Baseline Session 8. However, there were no further opportunities for him to remove tubes because he died for reasons unrelated to the experiment. The behavior of this kea was observed by only 1 other kea, fledgling male Pink, who did not solve the problem (the data of these 2 birds collected after the tube was removed for the first time were excluded from the baseline data). No other kea solved the task in the following 10 sessions. After almost twice the number of sessions following first success had taken place, it was decided to begin screw sessions. Although the presence of a screw in the pole for the following nine sessions increased the proportion of time the keas spent with a foot on the pole and the proportion of time they spent climbing the pole while exploring the tube, no kea managed to solve the task during these sessions (see Table 1; Mann-Whitney $U$ test, $N_{1}=15, N_{2}=8$; proportion of time feet on pole, $U=24, p=.018$; proportion of time climbing, $U=21, p=.003$ ). Thus, it is unlikely that the task will be solved by trial-and-error learning alone, yet it is not beyond the birds' capabilities.

\section{Test Phase}

Only 5 individuals approached the apparatus in both baseline and test phases of the experiment. The other individuals approached either in the baseline phase or in the test phase, but not in both. Again, when there were several birds within one body length of the apparatus, 2 birds seldom manipulated the tube at the same time (proportion of duration per session: median, .06; quartiles, $0-.13 ; n=$ 14), and joint action was quickly terminated by the dominant bird's displacing its subordinate.

Trained Model White performed 26 demonstrations of tube removal (duration of tube removal after contact with tube: median, 6 sec; quartiles, $4-9$ sec). Only the highest ranking juvenile male Orange was able to steal a removed tube from Model White. After Model White had removed 22 tubes in the first six test sessions (per-session median, 3.5; quartiles, 0.75-7), another kea, young adult male Green (in about his fourth summer), managed to solve the task in Session 7 for the first time and did so a second time during this session. Model White was not present during this or the next three sessions. In Sessions 8 and 9, no bird managed to remove the tube, but in Session 10 the highest ranking juvenile, male Orange, managed to solve the task for the first time. This juvenile dominated tube removal from then on and removed 58 (per-session median, 3; quartiles, 1-5) of the total of 87 (per-session median, 3; quartiles, 1-5) tubes removed. After male Orange solved this problem, trained Model White succeeded in removing the tube only four additional times (once each in Sessions 11 and 20 and twice in Session 26), and male Green succeeded a single time in Session 18.

In order to test other birds, we prevented solvers from approaching the apparatus after a few demonstrations in each session. Even so, no other kea managed to solve the task in the remaining 18 sessions of the test phase. The solving performance of male Orange after he had removed the tube for the first time was similar to that of Model White (duration of tube removal after contact with tube: median, 4 sec; quartiles, 3-6 sec). However, Model White always grasped the upper edge of the tube with his bill, whereas male Orange always pushed the tube upwards from the lower edge of the tube.

\section{Comparison of Baseline and Test Phase}

To look for evidence of social learning, we determined whether the birds changed their behavior in a way that made them, at least in principle, more likely to remove tubes after observing a demonstrator. However, time spent exploring the tube in relation to investigation events was not significantly different between individuals during baseline and test phases (Table 1; Mann-Whitney $U$ test: $\left.U=89, N_{1}=15, N_{2}=12, p=.96\right)$. Also, when the birds were exploring the tube, the relative time they spent moving the tube was not significantly different between individuals in baseline and test phases (Table 1; MannWhitney $U$ test: $U=53, N_{1}=15, N_{2}=11, p=.13$ ). Furthermore, there was no indication that the relative amount of time the tube remained in the different quarters of the pole during exploration differed between individuals during baseline and test phases (Table 2). The proportion of time spent in the quarter closest to the base of the apparatus did not decrease significantly (Mann-Whitney $U$ test: $U=64, N_{1}=15, N_{2}=11, p=.33$ ), and the proportion spent in the second quarter of the pole did not increase (Mann-Whitney $U$ test: $U=53, N_{1}=15, N_{2}=$ $11, p=.12)$. Thus, tube lifting did not become more frequent as a consequence of observing demonstrators.

There was a significant increase between test phase and baseline sessions in the relative time that keas grasped the

Table 2

Proportion of Time Individuals Spent Manipulating the Tube in Different Quarters of the Pole During Baseline and Test Phases

\begin{tabular}{lclccr}
\hline Phase & Subjects & Pole Quarter & Median & $Q 1$ & $Q 3$ \\
\hline Baseline & Nonsolvers $(n=15)$ & Base & .96 & .92 & 1.00 \\
& & Second & .04 & .00 & .06 \\
& & Third & .00 & .00 & .02 \\
& & Top & .00 & .00 & .00 \\
Test & \multirow{4}{*}{ Nonsolvers $(n=11)$} & Base & .93 & .87 & .99 \\
& & Second & .07 & .01 & .11 \\
& & Third & .00 & .00 & .02 \\
& & Top & .00 & .00 & .00 \\
& \multirow{5}{*}{ Solvers $(n=3)$} & Base & .51 & .30 & .68 \\
& & Second & .26 & .17 & .27 \\
& & Third & .13 & .13 & .27 \\
& & Top & .09 & .02 & .17 \\
\hline
\end{tabular}




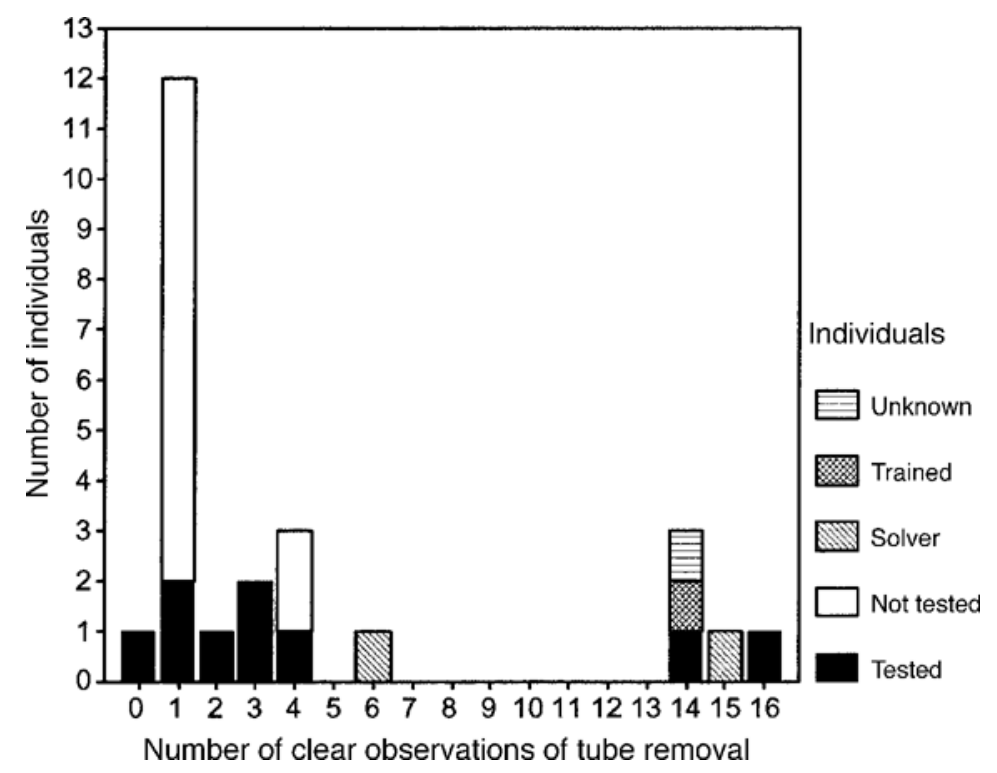

Figure 2. Number of tube-removal events that were clearly observed by the following different birds ("Unknown" refers to unbanded birds): "Trained" refers to trained Model White; "Solver," to male Orange and male Green; "Not tested," to banded birds that did not explore the apparatus; and "Tested," to banded birds that did explore the apparatus. Solvers Orange and Green were not considered after they had removed the tube for the first time on their own. See text for further explanation.

pole with their feet while exploring the tube (Table 1; Mann-Whitney $U$ test: $U=41, N_{1}=15, N_{2}=11, p=$ $.029)$, but there was no difference in relative duration of climbing while exploring the tube (Table 1; MannWhitney $U$ test: $\left.U=72, N_{1}=15, N_{2}=11, p=.48\right)$. The failure to increase frequency of climbing is not surprising, since climbing becomes relevant only when the tube is moved to higher levels of the pole, and explorers failed to significantly increase the height of the tube on the pole during the test phase. There was also no significant difference between baseline and test phases in duration of feet on the pole while exploring, when the tube was above the base quarter of the pole (the height from which solvers usually started to climb; Mann-Whitney $U$ test: $U=39$, $N_{1}=11, N_{2}=9, p=.42$ ).

Finally, there was no difference in the frequency of tearing events (tearings per second of tube exploration) between baseline (median, 0.006; quartiles, 0.001-0.014) and test phase (median, 0.009; quartiles, $0-0.025$; Mann-Whitney $U$ test: $\left.U=88, N_{1}=15, N_{2}=12, p=.92\right)$ or in the frequency of lifting events between baseline (median, 0.014; quartiles, 0.008-0.023) and test phase (median, 0.022; quartiles, 0.003-0.065; Mann-Whitney $U$ test: $U=62.5$, $\left.N_{1}=15, N_{2}=12, p=.18\right)$.

\section{Analyses of Particular Individuals}

When a demonstrator was removing a tube, we scanned the environment to check which of the birds present interrupted activity and seemed to direct their attention toward the demonstrator. This is a conservative measure of observing, since birds may have observed without giving clear signs. However, since not all individuals are equally likely to learn from a model (Huffman, 1996), this measure gives an indication of which individuals were most promising for case studies.

There seemed to be two groups of birds: those that did not often show clear signs of observing tube removal, and those that frequently did so, with a gap of numbers of observations between these two groups (Figure 2). We conducted case studies on the three individuals that most often showed clear signs of observing tube removal (among them Solver Orange). We also analyzed in more detail the data of the second solver, Solver Green, which did not belong to the group of birds that often showed clear signs of observation. Finally, a second case-study bird of this group was chosen; this bird observed tube removal about as many times as Solver Green but did not succeed in tube removal. Thus, the case-study birds were: subadult female Blue (henceforth labeled "Observer Blue ), which showed clear signs of observation 16 times but did not succeed in tube removal; juvenile male Orange (labeled "Solver Orange ) which solved the task after 15 clear signs of observation; and young adult male Red ("Observer Red), which showed clear signs of observation 14 times but did not solve the task. Young adult male Green showed clear signs of observation 6 times before solving the task (Solver Green). Finally, unsuccessful juvenile male Lime showed clear signs of observation 4 times. The data of 
solvers were considered only until they had solved the task for the first time.

All case-study birds showed clear signs of observing a model removing the tube from the pole throughout the test phase. Because these clear observation events were so well distributed among the birds' own attempts at the apparatus, we simply checked for correlations between changes in behavioral parameters and increased number of investigations in the course of the test phase, although we were mainly interested in whether the birds' performance changed with increasing numbers of observations.

The results of the case studies are shown in Tables 3 and 4. In summary, Solver Green succeeded in removing the tube in a single tube session and had high values in relative time spent exploring and moving the tube and in relative time spent with feet on the pole while the tube was above the base quarter of the pole. Other birds occasionally had similar scores but continued to manipulate the tube in an inefficient way, although they clearly observed a model more often than Solver Green did. Observer Blue increased her tube-lifting performance in that she kept the tube above the base quarter of the pole longer during the test phase than she did during baseline. But this improvement, as well as the increased use of feet by male Lime, was confined to the tubes while the tubes were at lower sections of the pole. In none of the case-study birds was

Table 3

Time Different Case-Study Individuals Spent Exploring the Apparatus During Different Experimental Phases and Proportions of Time Spent in Different Activities

\begin{tabular}{|c|c|c|c|c|c|c|c|c|}
\hline & \multirow{2}{*}{$\frac{\text { Solver Green }}{\text { Test }}$} & \multicolumn{2}{|c|}{ Solver Orange } & \multicolumn{2}{|c|}{$\begin{array}{c}\text { Individual } \\
\text { Observer Blue }\end{array}$} & \multicolumn{2}{|c|}{ Male Lime } & \multirow{2}{*}{$\frac{\text { Observer Red }}{\text { Test }}$} \\
\hline & & Baseline & Test & Baseline & Test & Baseline & Test & \\
\hline \multirow[t]{2}{*}{$n$} & 1 & 10 & 15 & 6 & 9 & 5 & 5 & 16 \\
\hline & \multicolumn{8}{|c|}{ Investigation Duration (Sec) } \\
\hline$M d n$ & 203 & $272.5^{\mathrm{a}}$ & $66^{\mathrm{a}}$ & $382^{\mathrm{b}}$ & $37^{\mathrm{b}}$ & 268 & 140 & 60.5 \\
\hline$Q 1$ & - & 77.25 & 23 & 98.25 & 12 & 114.5 & 71.5 & 16.25 \\
\hline Q3 & - & 527 & 172 & 717 & 322.5 & 701.5 & 789 & 119.75 \\
\hline \multirow[t]{2}{*}{$r_{s}$} & - & -.49 & -.18 & -.66 & .57 & .50 & -.50 & .09 \\
\hline & \multicolumn{8}{|c|}{ Proportion of Time Exploring Tube } \\
\hline$M d n$ & .87 & .64 & .57 & .37 & .35 & .61 & .44 & .31 \\
\hline$Q 1$ & - & .53 & .37 & .25 & .13 & .48 & .37 & .02 \\
\hline$Q 3$ & - & .75 & .73 & .59 & .65 & .67 & .72 & .62 \\
\hline$\tilde{r}_{s}$ & 2 & -.06 & .37 & -.14 & $.79 *$ & .80 & -.60 & .46 \\
\hline \multirow[t]{2}{*}{$n$} & 1 & 10 & 15 & 6 & 7 & 5 & 5 & 12 \\
\hline & \multicolumn{8}{|c|}{ Proportion of Time Moving } \\
\hline$M d n$ & .44 & .08 & .04 & $.03^{\mathrm{c}}$ & $.38^{\mathrm{c}}$ & .05 & .19 & .18 \\
\hline$Q 1$ & - & .02 & .00 & .00 & .15 & .00 & .07 & .07 \\
\hline$Q 3$ & - & .13 & .09 & .15 & .47 & .07 & .33 & .31 \\
\hline \multirow[t]{2}{*}{$r_{s}$} & - & -.44 & .41 & -.12 & .57 & .56 & -.80 & -.21 \\
\hline & \multicolumn{8}{|c|}{ PTFP } \\
\hline$M d n$ & .07 & .24 & .27 & .08 & .08 & $.03^{\mathrm{d}}$ & $.26^{\mathrm{d}}$ & .00 \\
\hline$Q 1$ & - & .11 & .00 & .00 & .00 & .01 & .14 & .00 \\
\hline$Q 3$ & - & .35 & .40 & .24 & .10 & .13 & .57 & .09 \\
\hline$r_{s}$ & - & -.28 & -.15 & -.37 & .41 & -.70 & $.90 *$ & .26 \\
\hline \multirow[t]{2}{*}{$n$} & 1 & 6 & 8 & 4 & 6 & 3 & 4 & 8 \\
\hline & \multicolumn{8}{|c|}{ PTFP While Tube Was Above Base Quarter of Pole } \\
\hline$M d n$ & .30 & .00 & .00 & .00 & .00 & .00 & .07 & .00 \\
\hline$Q 1$ & - & .00 & .00 & .00 & .00 & .00 & .00 & .00 \\
\hline$Q 3$ & - & .07 & .07 & .04 & .02 & .03 & .23 & .00 \\
\hline$\tilde{r}_{s}$ & - & .07 & -.66 & -.78 & .39 & -.87 & -.11 & - \\
\hline$n$ & 1 & 10 & 15 & 6 & 7 & 5 & 5 & 12 \\
\hline \multicolumn{9}{|c|}{ Proportion of Time Climbing With Tube } \\
\hline$M d n$ & .03 & .00 & .00 & .00 & .00 & .00 & .00 & .00 \\
\hline$Q 1$ & - & .00 & .00 & .00 & .00 & .00 & .00 & .00 \\
\hline$Q 3$ & - & .00 & .00 & .00 & .00 & .00 & .00 & .00 \\
\hline$r_{s}$ & - & - & .43 & - & - & - & -.35 & - \\
\hline
\end{tabular}

Note $-n$ is number of sessions. "Investigation is defined as the individual's being within one body length of the apparatus. "Proportion of time moving tube and "PTFP (proportion of time feet on pole) refer to time spent exploring the tube. Significantly different data $(p<.05)$ are labeled with a pair of the same letter (Mann-Whitney $U$ test) or as asterisks (Spearman rank correlation, $r_{s}$ : correlation coefficient). For the test phase, the data of Solver Orange and Solver Green were not considered after they had removed the tube for the first time. Solver Green and Observer Red did not investigate the apparatus during baseline. 
there an increase in either the relative time spent with feet on the pole while the tube was at higher levels or the time spent climbing the pole while manipulating the tube. Solver Orange did not increase his efficiency in tube lifting between baseline and test phases or within the test phase, but suddenly, during his tenth tube session, he solved the task.

\section{DISCUSSION}

In this study, free-living keas showed little improvement in their attempts to solve a tube-lifting task despite persistent interest in exploring and manipulating the ap-

Table 4

Proportion of Time Different Case-Study Individuals Spent Manipulating the Tube in Different Quarters of the Pole During Baseline and Test Phase

\begin{tabular}{|c|c|c|c|c|c|}
\hline $\begin{array}{l}\text { Experimental Phase } \\
\text { (No. of Sessions) }\end{array}$ & $\begin{array}{c}\text { Pole } \\
\text { Quarter }\end{array}$ & Median & $Q 1$ & $Q 3$ & $r_{s}$ \\
\hline \multicolumn{6}{|c|}{ Solver Green } \\
\hline \multirow[t]{4}{*}{ Test phase $(n=1)$} & Base & .78 & - & - & - \\
\hline & Second & .11 & - & - & \\
\hline & Third & .09 & - & - & \\
\hline & Top & .03 & - & - & \\
\hline \multicolumn{6}{|c|}{ Solver Orange } \\
\hline \multirow[t]{4}{*}{ Baseline $(n=10)$} & Base & .96 & .90 & 1.00 & .57 \\
\hline & Second & .03 & .00 & .08 & \\
\hline & Third & .00 & .00 & .02 & \\
\hline & Top & .00 & .00 & .00 & \\
\hline \multirow[t]{4}{*}{ Test phase $(n=15)$} & Base & .98 & .84 & 1.00 & -.41 \\
\hline & Second & .02 & .00 & .13 & \\
\hline & Third & .00 & .00 & .01 & \\
\hline & Top & .00 & .00 & .00 & \\
\hline \multicolumn{6}{|c|}{ Observer Blue } \\
\hline \multirow[t]{4}{*}{ Baseline $(n=6)$} & Base & $.99 \mathrm{a}$ & .92 & 1.00 & .12 \\
\hline & Second & $.01^{\mathrm{b}}$ & .00 & .08 & \\
\hline & Third & .00 & .00 & .00 & \\
\hline & Top & .00 & .00 & .00 & \\
\hline \multirow[t]{4}{*}{ Test phase $(n=7)$} & Base & $.87^{a}$ & .77 & .96 & -.39 \\
\hline & Second & $.12^{\mathrm{b}}$ & .04 & .19 & \\
\hline & Third & .02 & .00 & .05 & \\
\hline & Top & .00 & .00 & .00 & \\
\hline \multicolumn{6}{|c|}{ Male Lime } \\
\hline \multirow[t]{4}{*}{ Baseline $(n=5)$} & Base & .99 & .92 & 1.00 & -.56 \\
\hline & Second & .01 & .00 & .06 & \\
\hline & Third & .00 & .00 & .02 & \\
\hline & Top & .00 & .00 & .00 & \\
\hline \multirow[t]{4}{*}{ Test phase $(n=5)$} & Base & .91 & .81 & .96 & $.90^{*}$ \\
\hline & Second & .08 & .04 & .16 & \\
\hline & Third & .01 & .00 & .02 & \\
\hline & Top & .00 & .00 & .00 & \\
\hline \multirow{5}{*}{ Test phase $(n=12)$} & \multicolumn{3}{|c|}{ Observer Red } & & \\
\hline & Base & .97 & .92 & 1.00 & .03 \\
\hline & Second & .03 & .00 & .08 & \\
\hline & Third & .00 & .00 & .00 & \\
\hline & Top & .00 & .00 & .00 & \\
\hline
\end{tabular}

Note-Significantly different data $(p<.05)$ are labeled with a pair of the same letter (Mann-Whitney $U$ test) or asterisks (Spearman rank correlation, $r_{s}$ : correlation coefficient). For the test phase, the data of Solver Orange and Solver Green were not considered after they had removed the tube for the first time. Solver Green and Observer Red did not investigate the apparatus during baseline. paratus (839 investigation events in total). Only 3 out of 21 banded (plus a few unbanded) subjects managed to remove the tube from the pole, thereby gaining access to the attractive core. The keas also failed to show clear indications of social learning despite their apparent interest in successful manipulations by a trained conspecific (109 observations in total). At first glance, these findings provide strong support for Diamond and Bond's (1999) concluding remark about kea intelligence that "foraging skills are honed primarily through trial and error, and observational learning plays a minimal role (p. 149). Nevertheless, it is helpful to review the details of our analyses to better evaluate whether there might be any exceptions to this statement, and to discuss possible reasons for this failure and its implication for the understanding of social learning in animals.

If there are any signs of social learning hidden in the generally poor behavior of the keas in this study, then we should detect them in the actions of the two birds that solved the task in the test phase. Indeed, both solvers observed successful tube removal by the model before they solved the task on their own. Solver Orange failed during the baseline phase despite many attempts at the tube, but managed to solve the task in the test phase after a number of observation opportunities. Solver Green was not present in the baseline phase but succeeded in removing the tube in the test phase after 6 observation events. In contrast to the other solver, this young adult male engaged in very few attempts before solving the task. However, since neither of the birds solved the task immediately after observation of a demonstrator, it is impossible to make a strong case for social learning in either bird.

We also compared details of tube manipulation during baseline and test phase to see if there were any benefits from observation opportunities. Even unsuccessful attempts to remove the tube from the pole may involve some learning as a consequence of seeing a model perform rewarded actions. However, our analyses revealed that the keas did not benefit from observation. One of only two observed differences between performance of the keas during baseline and test phases was that Male Lime tended to keep his foot on the pole longer during test phase. However, since this bird tended neither to climb more nor to push the tube further toward the top of the pole, this increased contact with the pole produced a very limited improvement in performance.

Another kea, Observer Blue, spent a greater proportion of time in the test phase than during the baseline phase exploring the tube, as well as a greater proportion of time pushing the tube above the bottom quarter of the pole. These changes in behavior may have been caused by Observer Blue's attraction to the object, which the model manipulated in a very salient way (an example of stimulus enhancement; Spence, 1937). Since Observer Blue failed to use her feet to either grasp or climb the pole, her manipulations, like those of Male Lime, remained unsuccessful.

In sum, 4 keas showed an improvement in the foraging task, with 2 of them achieving true success. However, 
even if we consider all improvements in performance as a result of observation, the overall evidence for social learning remains poor.

Our findings were surprising for several reasons. First, performance of a demonstrator climbing the pole while lifting the tube with the bill is very conspicuous. Second, keas are highly motivated to manipulate objects and to carry objects in their bills (Diamond \& Bond, 1999; Keller, 1974). Third, the keas in this study were highly motivated to obtain the tube with its attractive core. Once they found the solution, they repeated it over a long period. Finally, solution of the tube-removal task has proven to be within the species' cognitive and physical capacity.

It turned out that it is difficult to investigate the natural spread of innovative behavior in a free-ranging population with the methods described in this study, since dominant Solver Orange was able to monopolize the apparatus. The latter is different from many natural food sources that are spatially more distributed. Nevertheless, by preventing the solvers, but not other birds, from approaching the apparatus, we were able to test whether other animals acquired the behavior. We also attempted to simulate dispersal of the food source by providing the apparatus to observers in the mountains around the village, in the absence of the dominant solver. However, encounters with birds away from our primary experimental sites were rare.

We conducted a pilot study with 5 captive keas in Vienna. Three of these captive keas solved the task very quickly when tested in isolation; 2 birds removed the tube in the first test session and 1, in the third. One of the remaining 2 birds failed in the first five sessions. This bird was then given nine demonstrations by a human model and solved the task instantly. The 5th bird failed during the first three sessions, then was given three opportunities to observe a proficient demonstrator and solved the task.

The most likely explanation for the superior performance of captive birds is their experience with other, relevant tasks. For instance, the animal caretaker often poked pieces of food onto the tips of twigs and branches in the aviary. However, time spent in object exploration does not always differ between captive and wild kea (Johnston, 1999; for general discussion, see Kummer \& Goodall, 1985; Tomasello, 1990, 1996; Whiten, 1993), and kea in the field also solved a string-pulling task (Johnston, 1999) that has been considered cognitively demanding (Heinrich, 2000). Nevertheless, the differences between captive and wild kea in tube removal were striking.

We suggest that two aspects of the tube-removal task may have rendered it difficult. First, it was necessary for the kea to coordinate pushing the tube with the beak and climbing the pole. Although neither of these two acts is difficult for a kea, the combination of these actions may be at the kea's limit. However, the string-pulling task also involves the use of both the bill and the feet, but it did not pose great difficulties for wild keas (Johnston, 1999).

A second difficulty of the tube-removal task, and in our eyes the crucial one, is the need for subjects to learn that the tube must not only to be lifted in order for the food reward to be accessed, but must also to be raised to the end of the pole. Generally, it is difficult for animals to learn during tool use that an object needs to be brought into an appropriate position in relation to another object (D. M. Fragaszy, personal communication, August 27, 2003).

To conclude, we suggest that the present study points to the importance of conducting field studies to explore the function of social learning in nature. A decade and a half after Galef's (1988) inspiring paper on social learning by animals in the psychology laboratory, and after heroic attempts to disentangle the mechanisms of social learning seen there, we still lack similar studies of the function and use of social learning in the wild. Although detailed comparative analysis has suggested ecological, structural, and life-history determinants of the relative contribution of social learning to reproductive success, evidence from field studies remains rare.

\section{REFERENCES}

AKins, C. K., \& Zentall, T. R. (1996). Imitative learning in male Japanese quail (Coturnix japonica) using the two-action method. Journal of Comparative Psychology, 110, 316-320.

AKINS, C. K., \& ZENTALL, T. R. (1998). Imitation in Japanese quail: The role of reinforcement of demonstrator responding. Psychonomic Bulletin \& Review, 5, 694-697.

Bond, A. B., Wilson, K.-J., \& Diamond, J. (1991). Sexual dimorphism in the kea (Nestor notabilis). Emu, 91, 12-19.

BREJAART, R. (1988). Diet and feeding behaviour of the kea (Nestor notabilis). Unpublished doctoral dissertation, Lincoln University, Canterbury, New Zealand.

Bugnyar, T., \& Huber, L. (1997). Push or pull: An experimental study on imitation in marmosets. Animal Behaviour, 54, 817-831.

CALL, J., \& CARPENTER, M. (2002). Three sources of information in social learning. In K. Dautenhahn \& C. L. Nehaniv (Eds.), Imitation in animals and artifacts (pp. 211-228). Edinburgh: MIT Press.

CARlier, P., \& Lefebvre, L. (1997). Ecological differences in social learning between adjacent, mixing populations of zenaida doves. Ethology, 103, 772-784.

ClARK, C. M. H. (1970). Observations on population, movements and food of the kea (Nestor notabilis). Notornis, 17, 105-114.

Coussi-Korbel, S., \& Fragaszy, D. M. (1995). On the relationship between social dynamics and social learning. Animal Behaviour, 50, 1441-1453.

Dawson, B. V., \& Foss, B. M. (1965). Observational learning in budgerigars. Animal Behaviour, 13, 470-474.

DiAmond, J., \& Bond, A. B. (1999). Kea, bird of paradox: The evolution and behavior of a New Zealand parrot. Berkeley: University of California Press.

Dolman, C. S., Templeton, J., \& Lefebvre, L. (1996). Mode of foraging competition is related to tutor preference in Zenaida aurita. Journal of Comparative Psychology, 110, 45-54.

Fawcett, T. W., Skinner, A. M. J., \& Koldsmith, A. R. (2002). A test of imitative learning in starlings using a two-action method with an enhanced ghost control. Animal Behaviour, 64, 547-556.

FisCheR, J., \& Hinde, R. A. (1949). The opening of milk bottles by birds. British Birds, 42, 347-357.

Fritz, J., Bisenberger, A., \& Kotrschal, K. (2000). Stimulus enhancement in greylag geese (Anser anser): Socially mediated learning of an operant task. Animal Behaviour, 59, 1119-1125.

Fritz, J., \& KotrSChal, K. (1999a). Social constraints and profitability of scrounging affect social learning. In K. Dautenhahn \& C. L. Nehaniv (Eds.), Imitation in animals and artifacts (pp. 20-26). Edinburgh: MIT Press. 
FritZ, J., \& KOTRSCHAL, K. (1999b). Social learning in common ravens, Corvus corax. Animal Behaviour, 57, 785-793.

GALEF, B. J., JR. (1988). Imitation in animals: History, definitions and interpretation of data from the psychological laboratory. In T. R. Zentall \& B. G. Galef, Jr. (Eds.), Social learning: Psychological and biological perspectives (pp. 3-28). Hillsdale, NJ: Erlbaum.

GiRAldeAU, L.-A., \& LefebVRe, L. (1987). Scrounging prevents cultural transmission in food-finding behaviour in pigeons. Animal Behaviour, 35, 387-394.

HeInRICH, B. (2000). Testing insight in ravens. In C. M. Heyes \& L. Huber (Eds.), The evolution of cognition (pp. 289-305). Cambridge, MA: MIT Press.

HEYes, C. M., \& DAWSON, G. R. (1990). A demonstration of observational learning in rats using a bi-directional control. Quarterly Journal of Experimental Psychology, 42B, 59-71.

HigGins, P. J. (ED.). (1999). Handbook of Australian, New Zealand and Antarctic birds. Melbourne: Oxford University Press.

Hinde, R. A., \& FisCheR, J. (1951). Further observations on the opening of milk bottles by birds. British Birds, 44, 392-396.

Huber, L., TABORSKy, M., \& ReChBerger, S. (2001). Social effects on object-exploration in keas. Animal Behaviour, 62, 945-954.

HUFFMAN, M. A. (1996). Acquisition of innovative cultural behaviors in nonhuman primates: A case study of stone handling, a socially transmitted behavior in Japanese macaques. In C. M. Heyes \& B. G. Galef, Jr. (Eds.), Social learning in animals: The roots of culture (pp. 267289). San Diego: Academic Press.

JACKSON, J. R. (1960). Keas at Arthur's Pass. Notornis, 9, 39-58.

JACKSON, J. R. (1963). The nesting of keas. Notornis, 10, 319-326.

JoHNSTON, R. (1999). The kea (Nestor notabilis): A New Zealand problem or problem solver? Unpublished master's thesis, University of Canterbury, Christchurch, New Zealand.

Kaiser, D. H., Zentall, T. R., \& Galef, B. G., JR. (1997). Can imitation in pigeons be explained by local enhancement together with trialand-error learning? Psychologcal Science, 8, 459-460.

Keller, R. (1974). Beitrag zur Biologie und Ethologie der Keas (Nestor notabilis) des Züricher Zoos [Contribution to the biology and ethology of the kea at the Zoo of Zurich]. Zoologische Beiträge, 22, 111-156.

Keller, R. (1975). Das Spielverhalten der Keas (Nestor notabilis Gould) des Züricher Zoos [Play behavior of keas at the Zoo of Zurich]. Zeitschrift für Tierpsychologie, 38, 393-408.

KubAT, S. (1992). Die Rolle von Neuigkeit, Andersartigkeit und sozialer Struktur für die Exploration von Objekten beim Kea (Nestor notabilis) [Role of novelty, oddity, and social structure for object exploration in kea]. Unpublished doctoral dissertation, University of Vienna.

KUMMER, H., \& GOODALL, J. (1985). Conditions of innovative behaviou in primates. In L. Weiskrantz (Ed.), Animal intelligence (pp. 203214). Oxford: Oxford University Press, Clarendon Press.

Lefebvre, L. (2000). Feeding innovations and their cultural transmis- sion in birds. In C. M. Heyes \& L. Huber (Eds.), The evolution of cognition (pp. 311-328). Cambridge, MA: MIT Press.

LEFEBVRE, L., \& GIRALDEAU, L.-A. (1994). Cultural transmission in pigeons is affected by the number of tutors and bystanders present. Animal Behaviour, 47, 331-337.

Nicol, C. J., \& POPE, S. J. (1994). Social learning in small flocks of laying hens. Animal Behaviour, 47, 1289-1296.

PотTS, K. J. (1969). Ethological studies of the kea (Nestor notabilis) in captivity: Nonreproductive behavior. Unpublished bachelor's thesis, Victoria University, Wellington, New Zealand.

RichARDSON, P. J., \& BOYD, R. (2000). Climate, culture, and the evolution of cognition. In C. M. Heyes \& L. Huber (Eds.), The evolution of cognition (pp. 329-346). Cambridge, MA: MIT Press.

Rosenblum, L. A., Kummer, H., NAdler, L. A., Robinson, J., \& SUOMI, S. J. (1989). Interface of field and laboratory-based research in primatology. American Journal of Primatology, 18, 61-64.

SHERRY, D. F., \& GALEF, B. G., JR. (1990). Social learning without imitation: More about milk bottle opening by birds. Animal Behaviour, 40, 987-989.

SPENCE, K. W. (1937). Experimental studies of learning and higher mental processes in infra-human primates. Psychological Bulletin, 34, 806-850.

Temple, P. (1996). The book of the kea. Auckland: Hodder Moa Beckett.

TOMASELlo, M. (1990). Cultural transmission in the tool use and communicatory signaling of chimpanzees? In S. T. Parker \& K. R. Gibson (Eds.), Languageand intelligence in monkeys and apes: Comparative developmental perspectives (pp. 271-311). Cambridge: Cambridge University Press.

Tomase Llo, M. (1996) Do apes ape? In C. M. Heyes \& B. G. Galef, Jr. (Eds.), Social learning in animals: The roots of culture (pp.319-346). San Diego: Academic Press.

Voelke, B., \& Huber, L. (2000) True imitation in marmosets. Animal Behaviour, 60, 195-202.

WhiteN, A. (1993). Human enculturation, chimpanzee enculturation and the nature of imitation. Behavioral \& Brain Sciences, 16, 538539.

Whiten, A., \& Custance, D. (1996). Studies of imitation in chimpanzees and children. In C. M. Heyes \& B. G. Galef, Jr. (Eds.), Social learning in animals: The roots of culture (pp. 291-318). San Diego: Academic Press.

Whiten, A., \& HAM, R. (1992). On the nature and evolution of imitation in the animal kingdom: Reappraisal of a century of research. $A d$ vances in the Study of Behavior, 21, 239-283.

Wilson, K. J. (1990). Kea: Creature of curiosity. Forest \& Bird, 21, $20-$ 26.

ZeNTALL, T. R. (1996). An analysis of imitative learning in animals. In C. M. Heyes \& B. G. Galef, Jr. (Eds.), Social learning in animals: The roots of culture (pp. 221-243). San Diego: Academic Press. 